\title{
ERRATUM
}

Koichi Takahashi · Masaru Yogo - Satoshi Ishibashi

\section{Stand development and regeneration during a 33-year period in a seral Picea glehnif forest, northern Japan}

Published online: 16 December 2005

(C) The Ecological Society of Japan 2005

\section{Ecol Res: DOI 10.1007/s11284-005-0093-2}

When this article was published online, Fig. 2c appeared incorrectly. The corrected Fig. 2 is shown below.

Fig. 2 Tree density (a), mean $\mathrm{DBH}(\mathbf{b})$, skewness of DBH frequency distribution (c) and the number of recruits (d) of $P$. glehnii (solid circle) and A. sachalinensis (open circle)
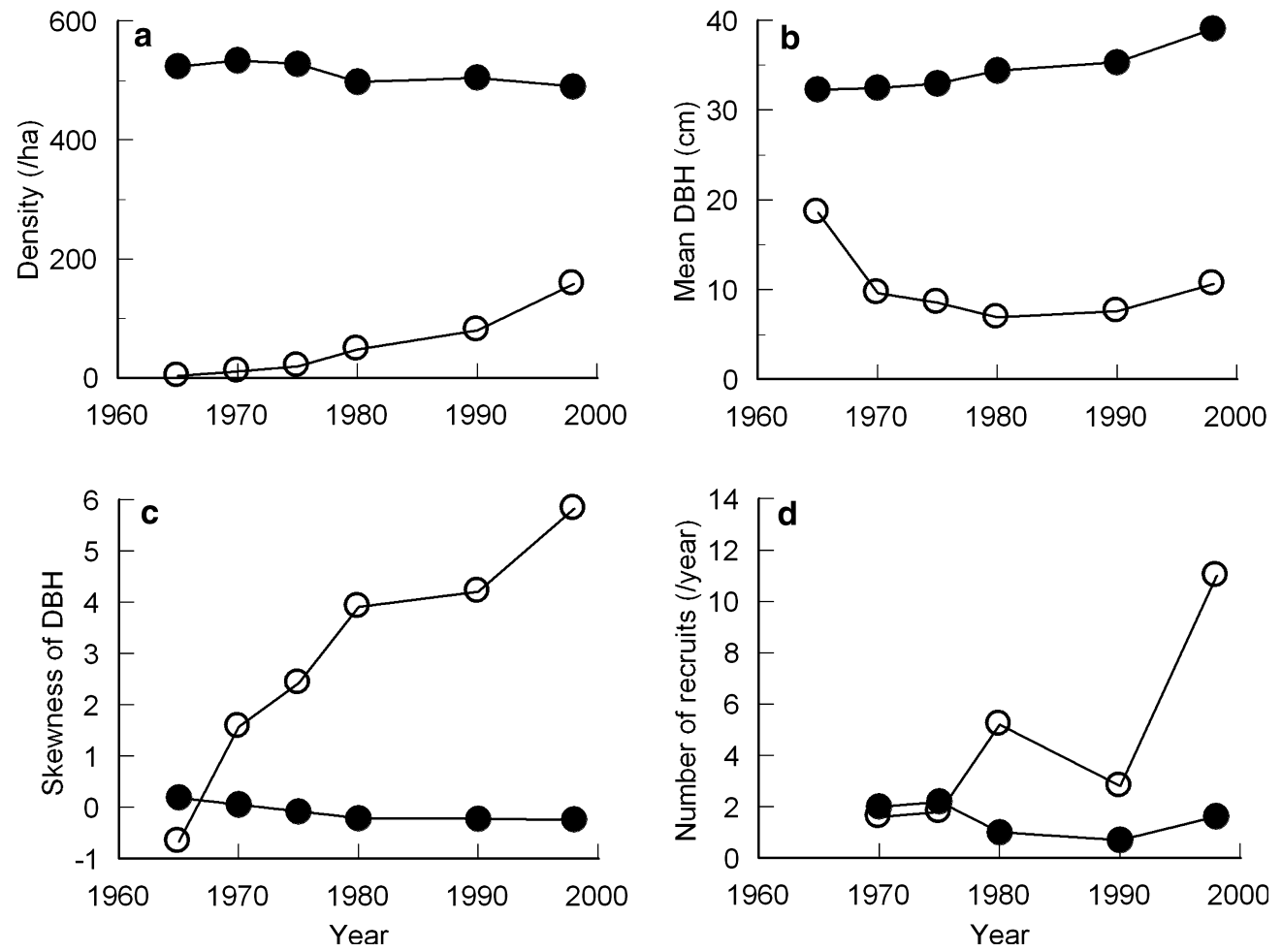

The online version of the original article can be found at http:// dx.doi.org/10.1007/s11284-005-0093-2

K. Takahashi

Department of Biology, Faculty of Science, Shinshu University, Matsumoto 390-8621, Japan

M. Yogo

Department of Forest Science, Faculty of Agriculture, Hokkaido University, Sapporo 060-0809, Japan

S. Ishibashi

Hokkaido Research Station, Forestry and Forest Products

Research Institute, Sapporo 062-8516, Japan
Present address: K. Takahashi $(\bowtie)$

Department of Biology, McGill University,

1205 Docteur Penfield, Montreal,

Quebec H3A 1B1, Canada

E-mail: koichit@gipac.shinshu-u.ac.jp

Present address: M. Yogo

Tomoku Company Limited,

Marunouchi-Mitsui Building,

Marunouchi, Tokyo 100-0005, Japan 